\title{
A linguagem poética lourenciana e sua relação com outras artes ${ }^{1}$
}

Valéria Alves Correia Tavares"

Prof. Dr. Roberto Abdala Junior ${ }^{* *}$

\section{Resumo}

As transformações ocorridas na maneira de se interpretar uma obra contribuem para a performance do leitor, do poeta e da própria linguagem poética. Recorrendo aos escritos de Bakhtin (1998), Benjamin (1994), Compagnon (2001), Hamburger (1975) e Zumthor (2010) intenta-se mostrar, neste artigo, como a relação da poesia com as outras artes estão inseridas nos versos de Edival Lourenço ${ }^{2}$. Pretende-se ainda, pensar a poesia contemporânea e em como ela pode introduzir uma nova constituição do sujeito lírico estabelecido pela linguagem poética inter-relacionada com outras artes. $\mathrm{O}$ recorte da subjetividade lírica presente nos poemas do escritor goiano serão analisados no sentido de entender a maneira como essa linguagem e a atuação do sujeito lírico se instauram.

Palavras-chave: Perda da aura. Linguagem poética. Edival Lourenço. Leitor.

\section{Perda da aura: a inserção de uma nova função social para a obra de arte}

No ensaio A obra de arte na era de sua reprodutibilidade técnica (1994), Walter Benjamin apresenta uma reflexão sobre como os meios técnicos de reprodução obscureceram a "aura" da obra de arte, e afirma que toda obra possui uma "aura" na qual será representada sua singularidade, "o aqui e agora" (BENJAMIN, 1994, p. 167). O conjunto de transformações apresentados por Benjamin vem modificar a própria noção de literatura

* Doutoranda em Performances Culturais na Universidade Federal de Goiás (UFG). Mestra em Teoria da Literatura pela Pontifícia Universidade Católica de Goiás (PUC-GO). Graduada em Letras pela Universidade Estadual de Goiás (UEG). E-mail: valeriacorreiahti@ hotmail.com

** Doutor em História pela Universidade Federal de Minas Gerais (UFMG). Mestre em Educação pela UFMG. Graduado em História pela UFMG. Professor da Faculdade de História (FH) da Universidade Federal de Goiás (UFG), leciona na graduação em História e nos Programas de Pós-Graduação em História e em Performances Culturais (Faculdade de Ciências Sociais - FCS/UFG). E-mail: abdala.performances@gmail.com

Data de submissão: 15 jan. 2020 - Data de aceite: 06 mar. 2020 http://dx.doi.org/10.5335/rdes.v16i1.8538 
enquanto arte, isto é, é possível perceber que a análise deste autor expõe uma existência única e autêntica da obra que após reproduções técnicas se diluirão mediante os novos meios de reprodutibilidade, fazendo com que esta perca a "singularidade", a "autenticidade" e a "unicidade".

A obra de arte pós-perda da aura passa a exercer, de acordo com os apontamentos benjaminianos, uma nova função social, na qual o conceito e a prática idealista cultural são superados e a construção humana e histórica passa a ser usufruída, adequada e realizada por qualquer pessoa. Servindo das palavras de Benjamin (1994, p. 171-172),

[...] no momento em que o critério da autenticidade deixa de se aplicar à produção artística, toda a função social da arte se transforma. Em vez de fundar-se no ritual, ela passa a fundar-se em outra práxis: a política.

O enfoque do texto está na análise acerca da designação que Benjamin apresenta sobre a tradição do caminho percorrido pela obra ao longo do tempo, trajetória que possibilita dizer algo não apenas sobre ela mesma, mas também sobre as inter-relações edificadas ao redor dela. São essas relações que conferem sentido ao conceito de autenticidade e à introdução da obra em certo contexto, assunto para o qual o referido autor apresenta fantásticas semelhanças entre o que escreveu sobre o estado da arte no seu tempo e o que vivemos atualmente, no que se refere à fruição artística.

Para entender toda proporção das harmonias necessárias por meio dos sofisticados processos de reprodução que a técnica colocou a nosso dispor, os objetos estéticos, antes restritos ao conhecimento e à contemplação de poucos, tornaram-se, a partir de então, disponíveis a um número cada vez maior de pessoas, este processo é denominado por Benjamin de "perda da aura", interpretando-o como um efeito de "dessacralização", uma vez que o ensaísta recorda que

[...] a autenticidade de uma coisa é quintessência de tudo o que foi transmitido pela tradição, a partir de sua origem, desde sua duração material até o seu testemunho histórico (BENJAMIN, 1994, p. 168).

Considerando os apontamentos do ensaísta, vale ressaltar a importância do diálogo entre a literatura e as diferentes artes, com o objetivo voltado para modernização, frente aos desafios apresentados atualmente, com vistas no leitor, que deverá assumir competências para cruzar leituras de diversas obras e governar o produto dessas leituras, além disso, conquistar competências que viabilizem o (re)conhecimento do objeto artístico. Sendo os meios tecnológicos dotados de linguagens diversas das esteticamente consagradas, seu aparecimento acabou por promover uma reconfiguração, tanto do modo de recepção quanto do próprio fazer artístico, de sua forma de produção 
e do papel que a arte hoje desempenha socialmente, frente a um mundo dominado pela técnica, que demandam novas respostas a seus anseios, angústias e questionamentos. No ensaio em questão, Benjamin (1994) chama a atenção para $o$ fato de que,

[...] em sua essência, a obra de arte sempre foi reprodutível, [...] e vem se desenvolvendo na história intermitentemente, através de saltos separados por longos intervalos (p. 166).

Pode-se dizer que a intensidade de tais transformações, conforme nos informa o próprio Benjamin, já era mencionada por Valéry em 1934:

Em todas as artes existe uma parte física, que não pode continuar a ser olhada nem tratada como outrora, já que não pode subtrair-se ao conhecimento e potência modernos. Nem a matéria, nem o espaço, nem o tempo são desde há vinte anos o que foram até então. É de se esperar que tão grandes inovações modifiquem toda a técnica das artes, agindo, desse modo, sobre a própria invenção, chegando talvez mesmo a modificar a própria noção de arte em termos mágicos (VALERY apud BENJAMIN, 1994, p. 179) ${ }^{3}$.

Sem muito esforço, pode-se ver que o texto de epígrafe se adequa plenamente na discussão contemporânea envolvendo a leitura como um todo e, em particular, confere competências ao leitor, para que detecte o objeto, leia-o e entenda a referência artística presente neste, seja qual for a forma como este se presentifica, além disso, estabelece diálogo com as diversas formas de arte, ciente de sua totalidade e, ainda, torna benéfico este conhecimento na vida ativa, de acordo com as características de sua realidade.

A partir dessa base, é válido sugerir que esse conjunto de transformações vem modificar a própria noção de literatura enquanto arte, em termos mágicos e pragmáticos, ou melhor, é possível destacar que, se a análise de Benjamin relativa à reprodutibilidade técnica potencializa a obra de arte, retirando sua "aura" mágica e modificando a percepção humana sobre ela, o mesmo pode se dar com a reprodutibilidade técnica das outras artes, que a partir da sincronia estabelecida por cada uma, reconfigura o objeto artístico e suas nuances, potencializando sua universalização, pois como Benjamin (1994) reproduz na imaginação:

[...] os conceitos seguintes, novos na teoria da arte, [...] podem ser utilizados para a formulação de exigências revolucionárias na política artística (p. 166, grifos do autor).

\section{A relação da poesia lourenciana com outras artes}

Para explorar a interface entre a literatura e as outras artes na poesia do autor goiano em questão, a partir da linha de análise intermidiática proposta por Benjamin (1994), percebe-se que, ao dotar-se de linguagens peculiares, os meios artísticos não apenas adotaram 
como subsídio elementos pertinentes a outros campos, mas logo constituíram um rico intercâmbio com as diversas formas de expressão artística emprestando-lhes, inclusive, muitas de suas escalas técnicas. No âmbito desse estudo, é válido questionar: como Lourenço evoca as outras formas de arte em conversa com a poesia lírica? Ou ainda, que razões levam à poesia lourenciana dialogar com outras artes?

Para responder a tais questionamentos, ressalta-se que o poeta reproduz 0 contato entre sua poesia e os demais tipos de artes no volume Poesia reunida (2014), uma vez que seus versos podem ser classificados como cinematográficos, pois proporcionam ao leitor uma sucessão de cenas conduzidas por imagens. Percebe-se, portanto que o que está em jogo ao criar esta relação é a necessidade de se construir uma linguagem performática, mesmo que cada esfera artística possua sua especificidade. Lourenço consegue, no decorrer de cada poesia, instaurar uma busca por aproximação da linguagem poética com outras modalidades artísticas, isso também é uma forma de legitimar-se.

Nesse sentido, Lourenço põe em cena uma marcação subjetiva na qual o uso de imagens narra detalhadamente acontecimentos, ambientes, cenas, espaços, num enquadramento utilizado de forma cinematográfica, que por sua vez, revela a limitação do olho humano e desvenda segredos. Assim, o eu lírico aponta perspectivas não apenas para a apropriação do texto cinematográfico pelo literário, como também sugere que ele busque recursos em outras linguagens. Sob este ponto de vista, é válido indicar que por meio de outros recursos artísticos a poesia lourenciana torna possível lançar um novo olhar sobre os objetos, vistos, em geral, até então, conforme sua utilidade e significados culturalmente adquiridos, transformando-os, justamente graças a essa versatilidade inicial, em uma forma de expressão rica e altamente eclética.

Conforme citado anteriormente, na leitura da poesia do autor goiano é possível perceber a existência da linguagem cinematográfica. Neste diálogo existente entre os dois gêneros, conforme recorda Mikhail Bakhtin (1998, p. 123), "realiza-se o jogo múltiplo dos discursos, seu entrelaçamento e seu contágio recíproco", mesmo porque, há uma mistura de combinações e possibilidades de intensificação de sentidos, isto é, existe a mesma hibridização, face às possíveis viabilizações do conhecimento artísticos existentes, tanto na poesia quanto no cinema, pois, conforme o teórico traz à lembrança,

[...] o modelo da linguagem na arte literária deve ser, de acordo com sua própria essência, um híbrido lingüístico (intencional): devem existir obrigatoriamente duas consciências lingüísticas; aquela que é representada e aquela que representa, pertencente a um sistema de linguagem diferente. Pois, se 
aqui não houvesse esta segunda consciência representante, esta segunda vontade de representação, não estaríamos diante de uma imagem da linguagem, mas simplesmente de uma amostra da língua de outrem, autêntica ou falsa (BAKHTIN, 1998, p. 157, grifos do autor).

Servindo do pensamento bakhtiniano, entende-se que o crítico sugere uma tomada de consciência diante da linguagem artística, seja esta representante ou representada pelas vontades individuais do autor, do personagem ou do próprio leitor. Portanto, o diálogo existente entre a linguagem da poesia em questão e a linguagem cinematográfica, torna-se uma "luz projetada" da escrita lourenciana, o que nos leva a entender o poema como uma entidade discursiva, por meio de uma linguagem contemporânea, numa dialogização com as outras artes.

Para expressar o plurilinguismo existente na poesia nota-se a presença do fluxo de consciência nos versos de Lourenço, sendo este, um dos fatores que revelam características do cinema, como por exemplo, a montagem, que além de organizar a narrativa, determina a duração dos planos, os cenários que compõem um determinado espaço e os personagens que têm a função representacional das pessoas, assim, ao ressaltar a fragmentação constrói-se uma estrutura textual próxima dos takes cinematográficos, conforme podemos observar nos versos a seguir: finalmente eu posso

- ó todos vós que me ouvis! -

finalmente eu posso

passear

pelas varandas baldias

entre teias e picumãs

debruçar

nos corrimões rangentes

sobre a balaustrada antiga

mirando a rua

que se consome no seu próprio prosseguir

como que cadenciando o ritmo

de meu corpo se exaurindo

enquanto flutua

(LOURENÇO, 2014, p. 18).

Ao realizar a leitura da estrofe, percebe-se que é como se o autor liberasse o personagem, deixando-o entregue à própria vontade, aos seus devaneios, resultando um texto que lembra a associação livre de ideias, de forma incoerente, desconexo, sem os nexos ou ligamentos sintáticos de um texto compostos gramaticalmente pelas estruturas consideradas corretas, reforçando a presença do fluxo de consciência.

Para sustentar as características cinematográficas, um narrador/protagonista é inserido no poema, este por sua vez tal como uma câmera capta os fatos, ora objetivos: "finalmente eu posso"; ora à distância como um grande plano: "mirando a rua"; ora bem de perto, como se fosse um close: "debruçar / nos corrimões rangentes"; ora como um plano americano: "de meu corpo se 
exaurindo / enquanto flutua"; ora como uma câmera subjetiva: "ó todos vocês que me ouvis". Como resultado, vale afirmar que o eu lírico, por meio de descrições objetivas e subjetivas, indica, orienta, lembra um olhar cineasta na construção detalhada da cena apresentada no poema, por intermédio de imagens específicas inseridas intencionalmente para a constituição daquele momento, porém, conforme lembra Bakhtin (1998, p. 124), "conservam habitualmente a sua elasticidade estrutural, a sua autonomia e sua originalidade linguística e estilística”.

A leitura dos versos citados anteriormente demonstra que a mensagem poética, representada pela subjetividade lírica proporciona ao leitor possibilidades de imaginar a cena da maneira que desejar o que, por outro lado, não é possível acontecer ao assistir um filme, pois este não oferece esta margem de criação para o espectador. $O$ que é possível acontecer no cinema é verificar-se um processo de transformação e transmutação de sucessivas referências intertextuais, sem que exista um ponto de origem visível. Estas referências podem ou não ser conscientes ou explícitas, mas se aplicam tanto à literatura quanto ao cinema, ou seja, o intertexto é sempre eminente.

Evidentemente que não se esgotam as relações entre a poesia de Lourenço e o cinema, e a ideia de conferir à reprodutibilidade técnica de ambos, com propriedades exponenciais que possibilitam assinalar a questão das transformações perceptivas nos versos e as reações que eles proporcionam a partir das múltiplas linguagens e/ou imagens cinematográficas, de forma mediada e intensificadora de processos conciliados pela técnica narracional utilizada, favorece ainda mais tais relações. Nessa vertente, não seria demais reproduzir alguma verossimilhança da reprodutibilidade técnica da escrita lourenciana com as palavras de Benjamin (1994), sobre a importância do filme na criação de novas assimilações e estímulos de outras sensações humanas:

O filme serve para exercitar o homem nas novas percepções e reações exigidas por um aparelho técnico cujo papel cresce cada vez mais em sua vida cotidiana. Fazer do gigantesco aparelho técnico do nosso tempo o objeto das inervações humanas - é essa a tarefa histórica cuja realização dá ao cinema o seu verdadeiro sentido (BENJAMIN, 1994, p. 174).

Por conseguinte, utilizar técnicas cinematográficas na poesia possibilita a Lourenço criar uma experiência sui generis de colocar em funcionamento um "gigantesco aparelho técnico" para o leitor compreender a pluralidade de técnicas e extensões possíveis, como seguimentos da reprodutibilidade expressa nos movimentos literário e cinematográfico, contemporâneos.

Sob os auspícios prepositivos, no viés da Poesia reunida do poeta em análise, entende-se que a relação entre a poesia e a música, extrai uma discussão da 
natureza desta simetria, como forma de refletir e compreender as manifestações acerca da compatibilidade e da equivalência existentes no diálogo entre estes dois gêneros, analisados a partir de uma ótica literária e musical, com perspectivas diacrônicas e sincrônicas, no contexto em que ambas se enquadram. Sob este ponto de vista, é válido citar Bakhtin (1998), quando o teórico sugere que:

[...] o papel do contexto que enquadra o discurso representado tem uma significação primordial para a criação de uma imagem da linguagem. $O$ contexto que enquadra, lapida os contornos do discurso de outrem como o cinzel do escultor, e entalha uma imagem de língua no empirismo fruto da vida do discurso; ele confunde e alia a aspiração interior da linguagem de outrem às suas definições exteriores objetivadas (BAKHTIN, 1998, p. 156).

Depreende-se da concordância entre as linguagens, musical e poética, uma abordagem que trata das afinidades existentes entre estas, visto que os traços comuns que se destacam no discurso crítico da maioria das obras literárias e/ou musicais é a existência de certo caráter simultâneo, numa analogia que, muitas vezes, demonstra-se apaixonada, outras programática, o que vem a configurar uma busca pelo estabelecimento de uma validação, por um tipo de estudo que ultrapasse a competência da análise do discurso linguístico nestas duas linguagens elencadas.

Sob esse ponto de vista, é possível verificar que a poesia lourenciana apre- senta uma compatibilidade também com a música, mesmo sabendo, conforme sugere Compagnon (2001, p. 68), que

[...] compreender, interpretar um texto é sempre, inevitavelmente, com a identidade, produzir a diferença, com o mesmo, produzir o outro: descobrimos diferenças sobre um fundo de repetições.

As ideias de Compagnon ilustram a teoria de que as interações estéticas e culturais entre literatura e música, ao mesmo tempo, apresentam características, apontam pormenores sintomáticos e se diferem em seus significantes, possibilitando o reconhecimento e a concessão, por meio de uma inter-relação perceptível em versos de Lourenço, pela interdisciplinaridade que este consegue frutificar e pelo interesse no papel da música no âmbito da cultura literária. Conforme lembra Bakhtin (1998, p. 201),

[...] toda linguagem só se revela em sua originalidade quando é correlacionada a todas as outras línguas integradas numa mesma unidade contraditória.

A provável intenção do poeta ao transferir para o eu lírico a percepção da estreita relação entre a dimensão linguística e a dimensão literária que envolve a significação das palavras, quando estas agregam o sistema semiótico dos versos, é perceptível no decorrer da leitura. Quando o poeta utiliza vários versos para construir liricamente a cena da experiência de ouvir o novo disco dos Beatles faz perceber uma interco- 
municação entre os diferentes gêneros utilizados na elaboração, o que permite o aperfeiçoamento da fruição do leitor, concretizando a tese de Käte Hamburger (1975) a respeito do tipo e experiência de leitura que a poesia lírica proporciona. Vejamos alguns versos do poema Pela alvorada dos nirvanas, nos quais a cena supracitada é narrada:

isso não são horas de rever aquele dia divisor

em que $o$ antenado Thioray

a uns poucos nos convidara

para estar no seu muquifo

numa noite de agosto

de fumaça e nuvem de aleluias

de sexta para sábado

e ouvir um disco novo

de um troço novo

que ele chamou de rock'n'roll

\section{[..]}

logo ao ver a capa

do propalado Long Play

tive tremor de epifania

aquela imagem mítica

Os Cabeludos de Liverpool

num rito de augúrio

fila indiana

enlevo de possuídos e a gente arranhando

aquele inglês ginasiano

mais de supor que de entender

em deslumbre total

sob os vapores da caninha

ligados naquele iê-iê-iê manhoso

nos eletrificando como quem segura

em fio desencapado de bruta voltagem

$[\ldots]$

falando agora tudo parece tão banal

mas o instante representou

para nós a travessia do limiar

de um mundo em que

uma rosa é uma rosa é uma rosa

e tudo estava certo

tudo estava o lugar

(LOURENÇO, 2014, p. 81/82, grifos do autor).

A presença da música na poesia lourenciana leva à reflexão sobre a ideia de que a comparação da poesia com outros tipos de arte está idealizada com diferentes olhares, uma vez que isso possibilita demonstrar a intertextualidade e, ainda, que este paralelismo da escrita dispõe da recordação dos signos da palavra, os quais gravam no cérebro do leitor um entrelaçado de significados, oriundos das propriedades disponíveis na palavra, seja ela literatura ou música, situação que pode ser comparada à reflexão de Bakhtin (1998, p. 191), a qual sugere que "as linguagens se correlacionam dialogi- 
camente e começam a existir umas para as outras".

Ao evocar a presença de Beatles no poema, pontua-se uma busca pelas razões que levam Lourenço a desenvolver possibilidades de relação entre a literatura e a música. A aparição do conjunto de rock inglês acontece de forma divertida, descrita por um eu lírico que, inicialmente, demonstra receio ao citar "Os Cabeludos de Liverpool" (LOURENÇO, 2014, p. 81), mas, posteriormente, a cada verso, assume que o instante em que ouviu, cantou e curtiu o novo vinil dos Beatles representou "a travessia do limiar" (p. 82) em sua vida. Neste momento da poesia, música e texto são combinados, referindo-se à aplicação de dois sistemas linguísticos. Por certo, para elucidar a linguagem recorremos à própria linguagem; e para analisar a música, também recorremos à linguagem, salvo poucas exceções. Essa diferença é uma fonte que não apresenta tradução teórica, isso lembra que, muitas vezes uma coisa não cabe na outra.

A partir dessa base, é válido supor que a relação entre a poesia lourenciana e a música, parte da realidade, e se encaminha numa busca por soluções na fantasia. Esse fantasiar, na medida em que o leitor degusta sua leitura, o transporta às verossimilhanças existentes $\mathrm{e}$ concede a capacidade de elaborar domínio, não apenas para viver e conviver com a linguagem poética, mas também para transformá-la, de acordo com cada interpretação.

Ao empregar em sua obra elementos que possibilitam uma leitura comparada entre as linguagens aqui analisadas, Lourenço preconiza a viabilidade de multiplicar-se, ampliar-se o conhecimento, as necessidades e as exigências tangíveis ao mundo do leitor. Mundo este que sugere a análise de imagens e marca a oralidade presentes nos versos, expondo elementos literários, por meio de uma relação que visa à construção imagética que se pode fazer ao ler essas palavras. Para tanto, a poesia lourenciana instiga o trabalho da relação entre o texto, a imagem, o cinema e a música, numa harmonia vinculada que permita, a partir do uso de estratégias de leitura a ampliação de seu repertório literário. Para tanto, é necessário ver, ouvir e sentir, mas acima de tudo, há a necessidade de envolvimento por parte do leitor e do poeta, pois a leitura demanda arte enquanto prática criadora e criativa. Neste caso, é imprescindível a concretização performática dos atores para que a relação pensamento e linguagem esteja intrinsicamente efetivada estabelecendo, ainda, o entrelaçamento das ideias para a reestruturação da linguagem artística, ação que levará o leitor ao entendimento da interconexão entre as diversas linguagens, confirmando, assim, a teoria de Paul Zumthor (2010, p. 166, grifo nosso): 
[...] performance implica competência. Além de um saber-fazer e de um saber-dizer, a performance manifesta um saber-ser no tempo e no espaço.

\section{Lourenciana poetic language and its relation with other arts}

\section{Abstract}

The transformations occurred in the way of interpreting a work contribute to the performance of the reader, the poet and the poetic language itself. Drawing on the writings of Bakhtin (1998), Benjamin (1994), Compagnon (2001), Hamburger (1975) and Zumthor (2010), this article attempts to show how the relation of poetry to other arts is inserted in the verses of Edival Lourenço. It is also intended to think of contemporary poetry and how it can introduce a new constitution of the lyrical subject established by poetic language interrelated with other arts. The cut of lyrical subjectivity present in the poems of the Goian writer will be analyzed in the sense of understanding the way in which this language and the performance of the lyrical subject are established.

Keywords: Loss of aura. Poetic language. Edival Lourenço. Reader.

\section{Notas}

1 Artigo apresentado aos professores da disciplina Cinema e Performances Culturais, cursada no primeiro semestre de 2018-1, para conclusão das atividades avaliativas.

2 Poeta, romancista e cronista goiano. Um representante da poesia contemporânea, apresenta um dos percursos mais sólidos e mais regulares dentre os poetas contemporâneos que produzem no estado de Goiás, o que pode ser observado tanto na poesia quanto na prosa.

3 A citação de Paul Valèry, encontrada nas páginas 103 e104 do livro "Pièces sur l'art", escrito em 1931, foi usada como epígrafe por Walter Benjamin na segunda versão de seu texto, em 1936, não estando presente na primeira versão, a que nos servimos aqui (BENJAMIN, 1994), cuja epígrafe contém apenas uma frase de Madame de Duras, "Le vrai est ce qu'il peut; le faux est ce qu'il veut".

\section{Referências}

BAKHTIN, Mikhail. Questões de Literatura e de Estética: A Teoria do Romance. $4^{\underline{a}}$ ed. São Paulo: Unesp, 1998.

BENJAMIN, Walter. A obra de arte na era de sua reprodutibilidade técnica. In: Magia e técnica, arte e política: ensaios sobre literatura e história da cultura. Tradução Sérgio Paulo Rouanet; prefácio Jeanne Maria Gagnebin. 7. ed. São Paulo: Brasiliense, 1994. (Obras Escolhidas, v. 1).

COMPAGNON, Antoine. $O$ demônio da teoria: literatura e senso comum. Tradução de Cleonice Paes Barreto Mourão, Consuelo Fortes Santiago. Belo Horizonte: Ed. UFMG, 2001.

HAMBURGER, Käte. O gênero lírico. In: A lógica da criação literária. Trad. Margot P. Malnic. São Paulo: Perspectiva, 1975. p. 167-209.

LOURENÇO, Edival. Poesia Reunida (1983 - 2013). / Apresentação de Iuri Pereira. São Paulo: Ex Machina, 2014.

ZUMTHOR, Paul. Introdução à poesia oral. Trad. Jerusa Pires Ferreira et al. Belo Horizonte: Editora UFMG, 2010. 